\title{
A REGIONALIZATION METHOD OF FLOW DURATION CURVE FOR ESTIMATING STREAMFLOW IN UNGAUGED CATCHMENTS
}

\author{
Ileana TĂNASE ${ }^{1}$, Cătălina PETRE ${ }^{1}$
}

\begin{abstract}
A Regionalization Method of Flow Duration Curve for Estimating Streamflow in Ungauged Catchments. Decision making in management and engineering is often requested for catchments where hydrological data is not available, like water resources forecasting, planning and operation and for different studies on physical and biochemical process.The Flow Duration Curve (FDC) represents the relationship between the magnitude and frequency of daily (or other time interval) streamflow for a particular river basin, providing an estimation of the percentage of time a given streamflow was equaled or exceeded over a historical period. Flow duration curves are considered an important tool for characterizing hydrological regimes and flow variability. The paper presents a regionalized model for predicting flow duration curve for ungauged catchments. This model was developed using a data set of 12 gauging stations with natural regime, in Siret river basin. The regional flow duration curve is based on multiple regressions between the flow with the $80 \%$ probability of occurrence from standardized flow duration curve, the hydrological response of soil types and the climate characteristics of the basin. The statistical model for estimating the flow duration curve is important for predicting natural flow statistics at ungauged sites and for impacts assessment on artificial influences within the Romanian rivers.
\end{abstract}

Keywords: regionalization, flow duration curve, regression, Siret river basin.

\section{INTRODUCTION}

The flow duration curve is a graphical representation of the frequency distribution of the flow regime and on the bases thereof is possible to determine the percentage of time when a specific flow is equaled or exceeded.

The flow duration curve requires gauged river data. Because the number of gauged rivers is very small, the models for predicting the natural flow at ungauged sites have been developed. There are many international techniques for estimating the flow regime at ungauged sites (Demuth, 1993). The most popular approaches for predicting flow duration curve for ungauged catchment is based on the cluster analysis and regression techniques relating flow statistics to physiographic and climatic characteristics (Young et al., 2000).

The paper will describe a statistical based hydrological model for predicting flow duration curve on catchment characteristics base, in Siret river

1 National Institute of Hydrology and Water Management, Bucharest, Romania, e-mail: ileana.tanase@hidro.ro, catalina.petre@hidro.ro 
basin. The described method is based primarily on the recent existing models for predicting natural flow statistics (Young et. al, 2000, Crocker et. al, 2003). This method for estimation flow duration curve in ungauged catchment consists in identifying multiregression relationships witch are suitable for the climatic and geomorphologic conditions of the analyzed catchments. The catchment characteristics include soils, rainfall and evaporation.

The flow duration curves are considered an important tool for characterizing natural flow regimes and flow variability as well as for identify the impacts of artificial influences. The estimation of flow duration curve in a river section is necessary for addressing problems related to hydropower generation, river and reservoir sedimentation, water allocation for human consumption and industry and ecosystem integrity.

\section{DATA AND METHODS}

The study is based on the flow data series analysis recorded at the 12 gauging stations, in Siret river basin, with natural regime (Figure 1 and Table 1), for the 1980-2013 period (the data were provided by the National Institute of Hydrology and Water Management). The corresponding basins of the analyzed gauging stations have been identified by using GIS framework and the characteristics were extracted of the catchment like soils, rainfall and evaporation. Based on those data, can be estimated flow duration curve in any section of the river from Siret river basin for which there is no direct hydrometric data.

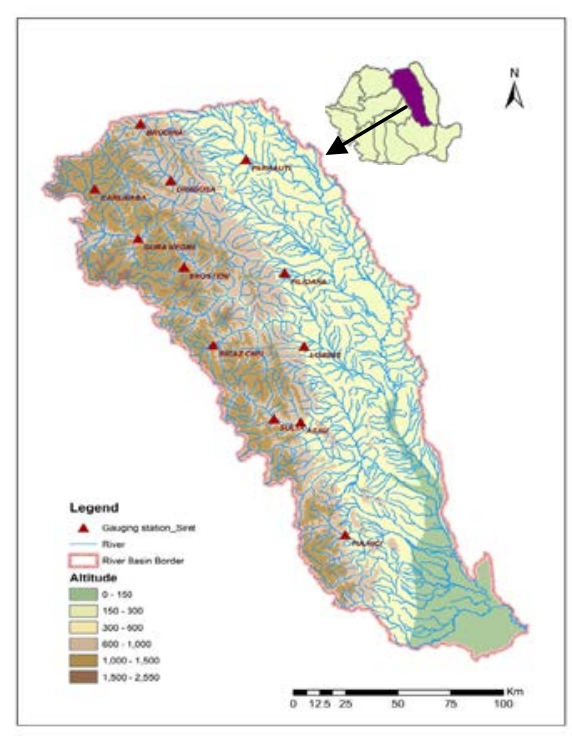

Table 1. The main characteristics of the analyzed gauging stations

\begin{tabular}{|c|c|c|c|c|}
\hline No. & $\begin{array}{c}\text { Gauging } \\
\text { station }\end{array}$ & River & $\begin{array}{c}\text { Drainage } \\
\text { area } \mathbf{( k m}^{2} \text { ) }\end{array}$ & $\begin{array}{c}\text { Mean } \\
\text { altitude (m) }\end{array}$ \\
\hline 1 & Asau & Asau & 203.4 & 951 \\
\hline 2 & Bicaz Chei & Bicaz & 181.4 & 1167 \\
\hline 3 & Brodina & Suceava & 364.4 & 990 \\
\hline 4 & Brosteni & Neagra & 334.1 & 1220 \\
\hline 5 & Carlibaba & Carlibaba & 111.2 & 1253 \\
\hline 6 & Dragosa & Moldovita & 474.2 & 934 \\
\hline 7 & Filioara & Agapia (Dalia) & 34.2 & 660 \\
\hline 8 & Gura Negri & Neagra & 310.3 & 1256 \\
\hline 9 & Luminis & Iapa & 67.6 & 745 \\
\hline 10 & Parhauti & Solonet & 210.8 & 467 \\
\hline 11 & Sulta & Sulta & 115.7 & 1041 \\
\hline 12 & Tulnici & Putna & 312.9 & 990 \\
\hline
\end{tabular}

Fig. 1. The map with the location of the analyzed gauging stations 
The Siret river basin is located in the east, north-east part of Romania, occupying most of the Moldavian Provence. It is the third-largest catchment area of any Danube tributary, and the whole surface of the river basin stretches four great landform units: Eastern Carpathians, Moldavia SubCarpathians, Moldavian Plateau, and Inferior Siret Plain. The climate in this area is a temperate one, with continental influences. The torrential character of the rivers in the Siret river basin can be amplified by the human interventions in the last years, especially by the massive deforestation in the Carpathians (Romanescu, 2009).

\section{Method description}

The method for flow duration curve estimation includes the following steps:

1. Plotting the standardized flow duration curve and select the values of the flow equaled or exceeded $80 \%$ of the time from the daily mean flow duration curve (Q80).

In order to minimize the influence of scale effects, the standardized (dimensionless) daily mean flow duration curve was used (figure 2). This can be achieved by various methods, the most common being the division the each daily mean flow with multiannual average flow of the data series (Smakhtin, et al., 1997).

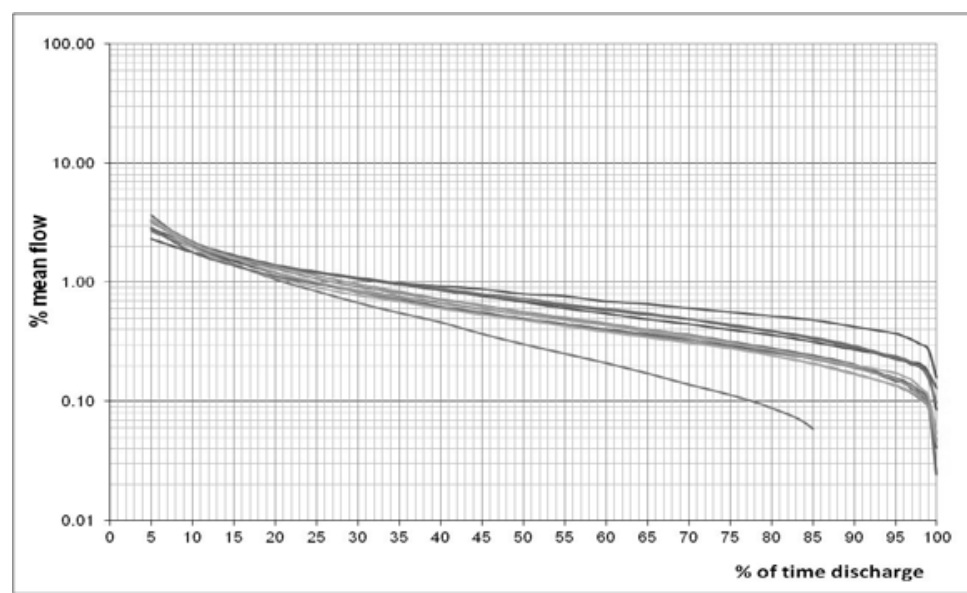

Fig. 2. The standardized flow duration curve for the analyzed gauging stations

Castellarin et. al, 2007, stated that "the dimensionless daily streamflow is a key signature of the hydrological behavior of the considered river basin and the probability distribution function is controlled by the geomorphologic and climatic characteristics of the basin itself".

\section{The Base flow index calculation}

The base flow index (BFI) represents the ratio of baseflow to total flow within the catchment (figure 3) and is calculated from each site by a hydrograph separation procedure (WMO, 2009). The values of the BFI index range between 0,15-0,2 from impermeable catchment to more than 0,95 for catchments with high storage capacity 
and stable flow regime. It was found that there is a strong relationship between the standardised flow and catchment hydrogeology (The Natural Environment Research Council, 1980). Cheng, 2012, state that "there are a significant relationship between the shape of flow duration curve and the BFI coefficient”.

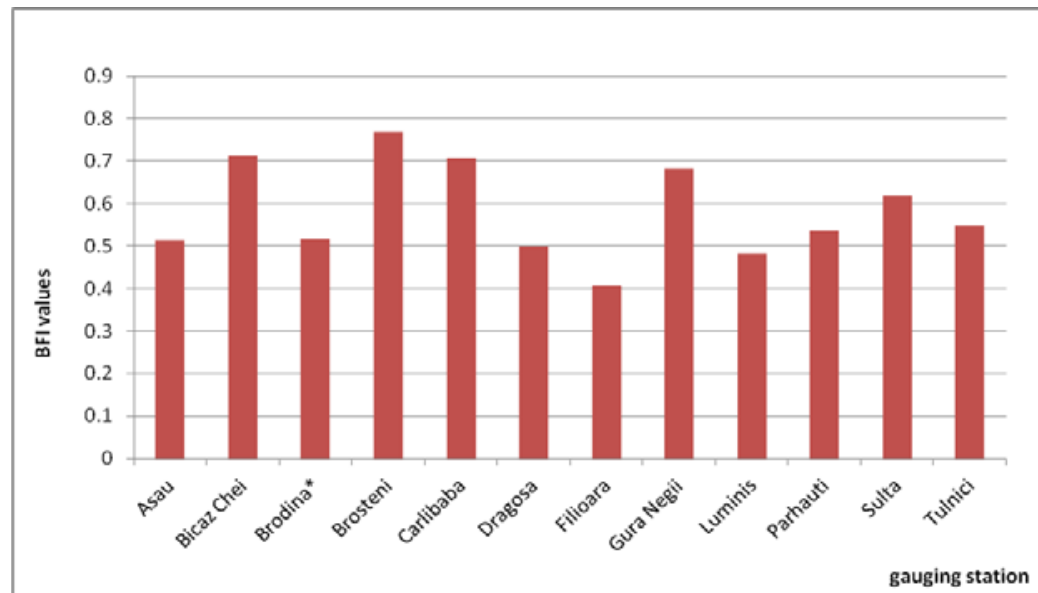

Fig. 3. The values of BFI for the analyzed gauging station

3. Define catchment boundary for the analyzed gauging stations

Using GIS interface and the topographic map, the catchment of each gauging station was digitized and the catchment area was estimated.

\section{Calculate fractional extent of soil classes}

The lower part of the flow-duration curve is governed by the base flow, such as the shape of curve is entirely dependent on the value of Q80. The shape of the FDC depends on the overall catchment soil permeability (Castellarin, 2007).

The soils are grouped in the 4 hydrological groups after an American classification system adapted to Romanian conditions, using texture classes practiced by ICPA (Chendes, 2011). Depending on the soil texture, the soils were classified into 4 hydrological groups: A, B, C and D. Group A comprises coarse textured soils, which have the lowest potential for drainage, while soils class D have fine texture (clay), which offer the greatest potential for water flows where infiltration is very low.

Using the GIS interface, overlay the map with boundary of the catchments and the map of soils and it was obtained the percentage of this 4 hydrological groups of soils in the analyzed catchments (fig. 4, 5).

\section{Calculate the BFIsoil statistics}

Using the multiple regression between BFI and hydrological soil classes (A,B,C,D) for the analyzed catchments the coefficients a were obtained for the equation 1 :

$$
\text { BFIsoil }=\sum_{i=1}^{4} a_{i} \text { SOILGP }_{\bar{i}}
$$


where, SOILGP $\mathrm{i}_{\mathrm{i}}$ hydrological soil groups ( $\mathrm{i}=$ hydrological soil classes), $a_{i}$ - coefficient for each soil class obtained from the regression equation.

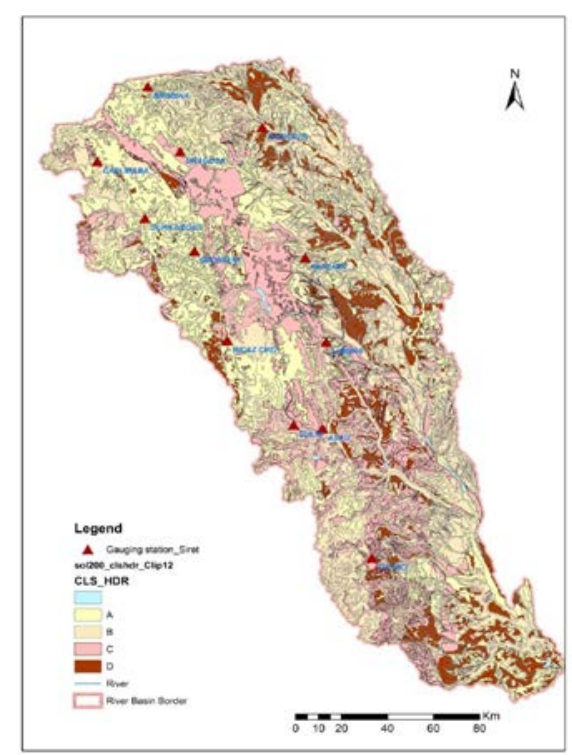

Fig. 4. The map with the hydrological soil clases for the entire river basin

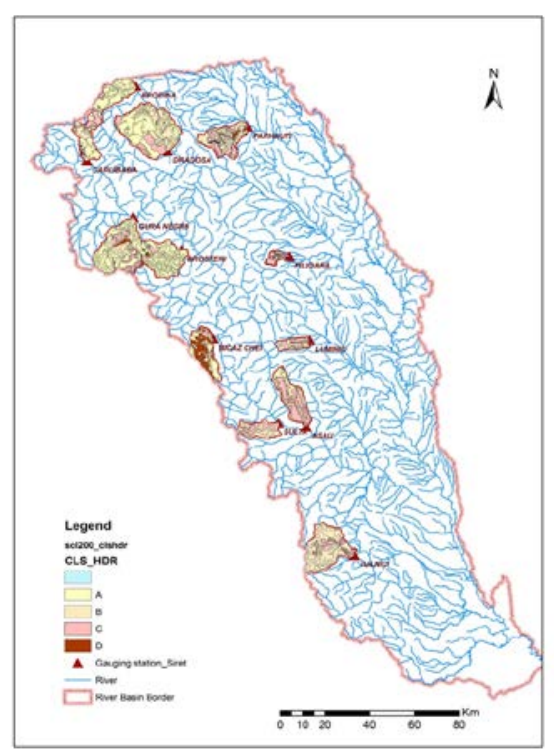

Fig. 5. The map with the hydrological soil clases for the analyzed catchments

6. Calculate an average annual rainfall and average annual evaporation for the catchment

This calculation procedure is based on GIS interface and involves overlaying the map of boundary catchment onto the map with average annual rainfall and the map with average annual evaporation (fig. 6 and 7) and calculating an average value for the each catchment.

\section{Calculate standardized Q80}

This step consist in the application of multiple regression between Q80 and BFISOIL and mean rainfall values of the catchments. The mean rainfall values are considered as a surrogate measure for seasonality (Croker et al, 2009).

8. Identify the standardized flow duration type curve associated with the estimated Q80

An important step in determining the regional models for predicting/estimating the flow duration curve in ungauged sites is grouping the types of standardized flow duration curve into flow regime classes (Ganora, 2009). These regime classes represent a starting point for daily mean flow duration curve regionalization according to environmental factors with major influence on average daily flow such as base flow, hydrological soil classes etc. 


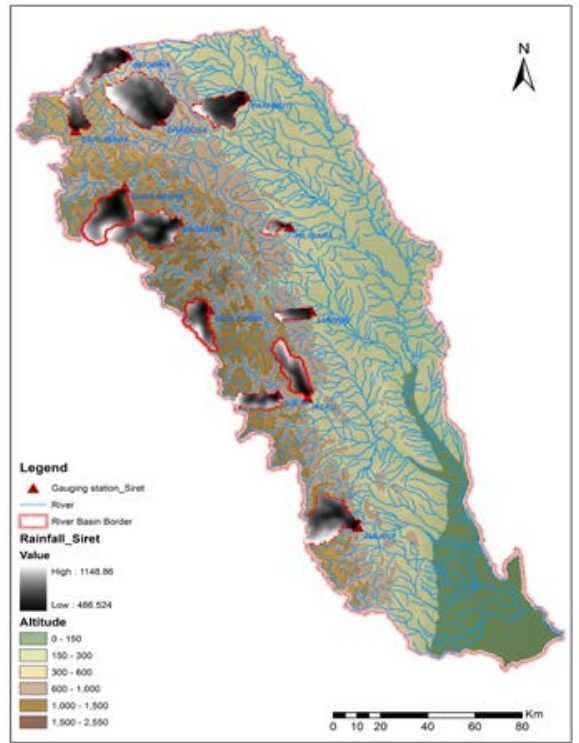

Fig. 6. The map with the mean annual rainfall for the analyzed catchments

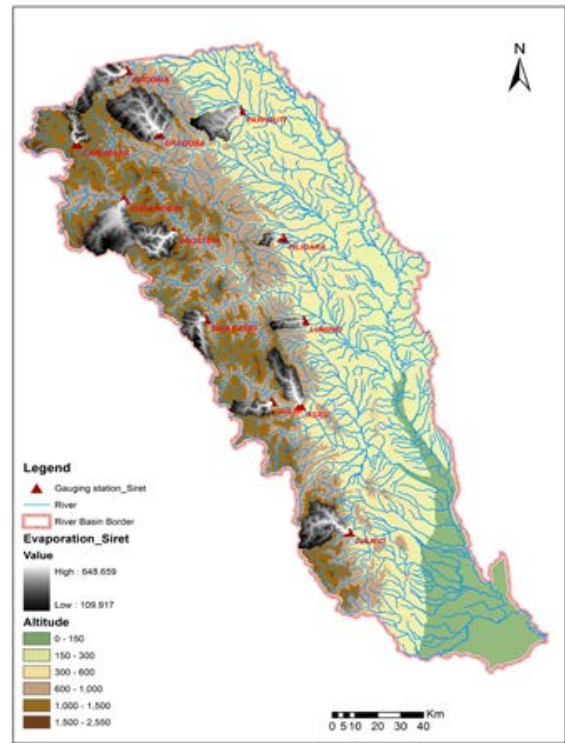

Fig. 7. The map with the mean annual evaporation for the analyzed catchments

The estimated value of Q80 is used to select a family of type curves from Q80 classes obtained from pooling standardized curves of the analyzed catchment. If the estimated Q80 doesn't coincides with the type curve, the predicted value of Q80 will be generated by linear interpolation between the curves.

9. Estimate the mean flow using simple water balance model and calculate the final Q80 value

Once identified the standardized flow duration curve, the final step in the estimation procedure is resizing with the estimated values of the mean flow.

The mean flow for ungauged sites is estimated using a conceptual balance model between average annual rainfall and annual evaporation (Young et. al, 2000). It is considered that the average annual runnof depth $(\mathrm{H})$ represent the difference between annual average rainfall (R) and evaporation (E). For basins with annual average rainfall (R) higher than $850 \mathrm{~mm}$, the evaporation is equal to the potential evaporation (E). For the catchments where annual average rainfall below the $850 \mathrm{~mm}$, the evaporation is reduced by the coefficient (r) which reflects the soil moisture deficit (equation 2).

$$
H=R-(r * E)
$$

where, $\mathrm{H}$ (mm/year) - average annual runnof depth, $\mathrm{R}$ (mm/year) - annual average rainfall, $\mathrm{E}$ ( $\mathrm{mm} /$ year) - average annual evaporation. 


\section{RESULTS}

A statistical multiple regression between the data obtained in the analyzed catchments from Siret river basin (Q80, BFI, soils component and the mean annual rainfall and evaporation) was developed.

From the multiple regression between the values of BFI and fractional extent of the soils grups results the following equation:

$$
\text { BFIsoul }=0,162+0,06 * A+0 * B-0,308 * C-0,089 * D
$$

From the multiple regression between the values of Q80, BFISOIL and mean rainfall of the catchments results the following equation:

$$
Q_{80}=\frac{0,714 * B_{F I s o i l}^{2,2}}{R}
$$

Using these equations, the standardized flow duration curve (Q80) in each section from Siret river basin can be determined. The mean daily flow duration curve can be obtained from rescaling the standardised flow duration curve by estimate annual mean flow. The annual mean flow is estimated using the balance model between average annual rainfall and annual evaporation (equation 2). The relationship between the mean rainfall and the coefficient $r$ was derived from the data catchment using the linear regression. The errors for linear regression are below $25 \%$.

$$
r=0,0023 * R-0,675
$$

The standard error for the multiple regression is about 0,1 and the model explaines approximately $62 \%$ of the variance. The weakness of this approach was the insufficient number of gauging station in a natural regime.

\section{CONCLUSIONS}

The present study shows a method for regionalization and estimation flow duration curve for the catchments without hydrometrical data, based on the attributes of the catchment and regression techniques, in the Siret river basin. The regionalization of flow duration curve provides information on ungauged basins based on the physiographic and climatic parameters of the catchment. The regression methods offer the possibility that a specific runoff to be estimated based on their relationship with soil catchment and climatic attribute through analytical expression.

The flow duration curve provides a convenient means for studying the natural flow characteristics of streams and for comparing a basin with another. The estimating natural low flow regime at ungauged sites is important for planning of 
water supply schemes and impacts assessment of artificial influences within the catchments.

In Romania, many rivers are not gauged for long-term continuous monitoring. The regional regression equations need to be extended to other basins following that to try a regionalization for the entire country.

\section{REFERENCES}

1. Castellarin, A., Camorani, G., and Brath, A. (2007), Predicting annual and longterm flow-duration curves in ungauged basins, Adv. Water Resour., 30, 937-953

2. Chendes, V. (2011), Water resources in curvature Subcarpathians. Geospatial assessments, Editura Academiei, București, ISBN 978-973-27-2131-5, PhD thesis

3. Cheng L., Yaeger M, Viglione M. A., Coopersmith E., S. Ye, and Sivapalan M., (2012), Exploring the physical controls of regional patterns of flow duration curves - Part 1: Insights from statistical analyses, Hydrol. Earth Syst. Sci., 16, 4435-4446

4. Croker K M., Young A.R., Zaidman M. D. \& Rees H. G (2003), Flow duration curve estimation in ephemeral catchments in Portugal, Hydrological Sciences Journal, 48:3, 427-439, DOI: 10.1623/hysj.48.3.427.45287

5. Smakhtin, V. Y., Hughes, D. A., and Creuse-Naudin, E., (1997) Regionalization of daily flow characteristics in part of the Eastern Cape, South Africa, Hydrol. Sci. J.-J. Sci. Hydrol., 42, 919-936.

6. Romanescu G. (2009), Siret river basin planning (Romania) and the role of wetlands in diminishing the floods, WIT Transactions on Ecology and the Environment, Vol 125, 2009 WIT Press

7. Young, A. R., Gustard, A., Bullock, A., Sekulin, A. E. and Croker, K. M., (2000), A river network based hydrological model for predicting natural and influenced flow statistics at ungauged sites: Micro LOW FLOWS. Sci. Total Environ., 251/252, 293-304

8. Demuth, S., (1993), Untersuchungen zum Niedrigwasser in West Europa. Freiburger Schriten zur Hydrologie, Institut fur Hydrologie Band 1, 224pp

9. Ganora D., Claps P., LaIo F. and VIglIone A., (2009), An approach to estimate nonparametric flow duration curves in ungauged basins, ” Water Resour. Res., 45, W10418, doi:10.1029/2008WR007472

10. *** (1980), Low Flow Studies Report,. Institute of Hydrology. Wallingford, UK

11. *** (2009), Low-flow Estimation and Prediction, WMO Operational Hydrology Report No. 50

12. *** NIHWM - Hydrological database

13. $* * *$ NIHWM -Map of evaporation

14. *** NIHWM - Map of soil (ICPA)

15. *** NMA - Map of annual rainfall 